\section{Technical and Socioeconomic Challenges to Setting and Implementing Priorities in North American Rosaceous Fruit Breeding Programs}

\author{
Chengyan Yue ${ }^{1}$ \\ Department of Horticultural Science and Department of Applied Economics, \\ University of Minnesota, Twin Cities, 1970 Folwell Avenue, St. Paul, MN 55108
}

\author{
R. Karina Gallardo ${ }^{2,7}$ \\ School of Economic Sciences, Tree Fruit Research and Extension Center, \\ Center for Precision Agriculture and Automated Systems, Washington State \\ University, 1100 N. Western Avenue, Wenatchee, WA 98801
}

Vicki A. McCracken ${ }^{3}$

School of Economic Sciences, Washington State University, P.O. Box 646210, Hulbert Hall 101, Pullman, WA 99164

James Luby ${ }^{4}$

Department of Horticultural Science, University of Minnesota, Twin Cities, 1970 Folwell Avenue, St. Paul, MN 55108

James R. McFerson ${ }^{5}$

Washington Tree Fruit Research Commission, 1719 Springwater Avenue, Wenatchee, WA 98801

Lan Liu ${ }^{6}$

Department of Applied Economics, University of Minnesota, Twin Cities, 1970 Folwell Avenue, St. Paul, MN 55108

\section{Amy Iezzoni ${ }^{4}$}

Department of Horticulture, Michigan State University, East Lansing, MI 48824-1325

Additional index words. production-driven, market-driven, market stakeholders, resource availability, trait selection Abstract. Rosaceous crops (e.g., almond, apple, apricot, caneberry, cherry, pear, peach, plum,
rose, and strawberry) contribute to human health and well-being and collectively constitute the
economic backbone of numerous North American rural communities. We conducted a survey of
U.S. and Canadian rosaceous fruit crop breeders to assess priority setting in their programs,
sources of information for setting priorities, and challenges in making technical and management
decisions. Input from producers and consumers was most important in establishing breeding
program targets, although respondents' direct interaction with consumers was not frequent.
Breeding targets and management decisions were mostly associated with the breeder's type of
organization, scope and range of crops, and intended use of the crop (fresh, processed, or both).

Received for publication 20 Apr. 2012. Accepted for publication 13 July 2012.

This work was partially funded by USDA's National Institute of Food and Agriculture-Specialty Crop Research Initiative project, RosBREED: Enabling marker-assisted breeding in rosaceae (2009-51181-05808).

${ }^{1}$ Assistant Professor and Bachman Endowed Chair in Horticultural Marketing.

${ }^{2}$ Assistant Professor and Extension Specialist.

${ }^{3}$ Professor and Associate Director.

${ }^{4}$ Professor.

${ }^{5}$ Manager.

${ }^{6} \mathrm{Ph}$.D. student

${ }^{7}$ To whom reprint requests should be addressed; e-mailkarina_gallardo@wsu.edu. health and well-being, rosaceous crop producers and processors constitute the economic backbone of numerous U.S. and Canadian rural communities. Rosaceous crop breeding programs have a long history of introducing cultivars with superior characteristics for production, pest and disease resistance, postharvest handling and storage, sensory properties, and consumer appeal, thus contributing to industry profitability, environmental sustainability, and consumer choice.

Plant breeding, like any other new product development activity, is a process that creates value for stakeholders in the supply chain: producers, processors, packers and shippers, retailers, and consumers (Solomon and Stuart, 2003). Because there is considerable evidence indicating market-driven businesses are more likely to be successful than production-driven businesses (Solomon and Stuart, 2003), it seems useful to investigate if this is the case for rosaceous crop breeding programs.

Plant breeding programs require significant financial, human, and time resources, especially for perennial tree crops with long juvenility and generation times such as rosaceous tree fruit crops. Even rosaceous crops with shorter juvenility, like strawberry, caneberries, and rose, demand increased horticultural management compared with most row crops (Gallardo et al., 2012). Any efficiency introduced into such a breeding framework can reduce costs and provide a quicker impact for all interested parties in the supply chain. A critical first step would be to assess current breeding program practices to determine how targets are determined and prioritized and how technical and socioeconomic challenges affect the determination and implementation of breeding priorities.

To our knowledge, no such study has systematically investigated North American rosaceous crop breeding practices and challenges. We chose to focus our initial investigation on rosaceous fruit crops but expect the results would provide valuable insights for non-fruit rosaceous crops as well as other specialty crops. This study comprises four objectives: 1) to identify the most relevant interested parties influencing breeders' setting of priorities; 2) to assess breeders' technical considerations influencing trait selection; 3) to identify the challenges faced when determining and implementing priorities; and 4) to explore the differences in the practices and challenges among breeders focused on different crops from different organizations (university, federal government, or private company) and with different intended crop use (fresh vs. processing markets). This study is based on the same survey of North American rosaceous crop breeding programs as the one used in Gallardo et al. (2012), which determined the relative importance of traits and the likelihood of selection for the most important traits. Together, these complementary studies constitute the initial effort of a comprehensive investigation of the preferences and values interested parties in the supply chain place on fruit and plant characteristics for rosaceous fruit crops. It is 
important to recognize that this survey deals specifically with perceptions of rosaceous breeders. Subsequent surveys are underway to focus on perspectives of various members of the supply chain, including producers, market intermediaries, and consumers.

\section{Materials and Methods}

We used an Internet survey to investigate rosaceous breeders' current practices and the challenges faced in their breeding programs. We identified and surveyed the entire population of rosaceous breeding programs (60 in total) in the United States and Canada. To come up with the questions to be included in the survey, we conducted in-person interviews with 14 breeders representative of each crop focus and employing organization. We chose the Internet because results tend to be available faster and more accurate relative to those from telephone or face-to-face interviews (McCullough, 1998). The survey asked about different aspects of breeding programs. Questions included rating the importance of the needs of various interested parties (producers, consumers, wholesalers, nursery, own experience, colleagues), communication with these parties, and the level of importance of technical and socioeconomic challenges affecting the determination and implementation of program priorities. The survey also included questions regarding the relative importance of specific fruit traits. Finally, it asked about general program aspects such as crops bred, if crops bred were intended for fresh or processed market, program location and affiliation (university, government, or private company), and years of experience of the breeder.

Specific questions of interest included breeders' ratings of the importance of factors affecting the selection of a trait for inclusion in their program (using a 0 to 10 continuous scale, $0=$ very unimportant and $10=$ very important). These factors included level of importance of the needs of interested parties, technical considerations, and challenges faced when determining and implementing breeding trait priorities. This section also included questions about the frequency of interaction between breeders and various interested parties and the communication channels used.

We obtained responses from 40 different breeding programs, but six were incomplete and not used in this study. The 34 complete responses represent a $57 \%$ response rate. We conducted $t$ tests to evaluate if breeder ratings differed significantly between the considerations/parties for each of the analyzed survey questions.

We used double-bounded Tobit models to identify the main factors that influence breeders' ratings ( 0 to 10 scale with ratings left-censored at 0 and right-censored at 10 ). This approach uses the unobservable, underlying latent variable $\left(\mathrm{Y}^{*}\right)$ to express the observed dependent variable (Y) (Greene, 2007). This vector of dependent variables includes measures of the importance of the needs of interested parties and technical considerations and challenges breeders face when setting priorities and selecting a trait for inclusion in a breeding program. We express the unobservable dependent variable $\mathrm{Y}^{*}$ as a function of a vector of independent variables $\mathrm{X}$ by

$$
Y^{*}=X \beta+\varepsilon ; \varepsilon \sim \operatorname{Normal}\left(0, \sigma^{2}\right)
$$

where $\beta$ is the vector of unknown coefficients and $\varepsilon$ are the error terms that are assumed to follow a normal distribution with zero mean and SD of $\sigma$. The observed dependent variables are represented by

$$
Y=\max \left(0, Y^{*}\right) \text { and } Y=\min \left(Y^{*}, 10\right)
$$

The independent variable vector $\mathrm{X}$ includes information on fruit type, breeder and program information, type of crops, and the intended use of the fruit crop. Descriptions of the independent variables are listed in Table 1.

\section{Results}

Summary statistics and pairwise $\mathrm{t}$ test results between breeder ratings. Summary statistics of surveyed breeding programs in Table 1 illustrate we successfully captured a range of crop foci. Table 2 presents summary statistics for ratings of the relevance of interested parties, the importance of technical considerations, and the challenges faced when determining and implementing priorities when selecting a trait for inclusion in a breeding program. To examine if there are significant differences across breeders' ratings for the importance of interested parties and other factors influencing their setting of priorities when selecting traits for inclusion in their programs, we conduct pairwise $t$ tests, reported in Table 3. For example, we test if the mean rating for producer needs is significantly different from the ratings for consumer needs/preferences, wholesaler needs, nursery feedback, etc.

Results in Table 3 allow the identification of three tiers of importance for the interested parties/considerations influencing breeders' priority setting decisions. The first tier depicts the most important parties/considerations including producers, consumers, breeders' own experience, and the intended use of the crop; the second tier includes wholesalers, nurseries, experience of colleagues/other breeders, marketers, and retailers; and the third tier includes funding agencies and available premiums. Breeders consider the parties on the two ends of supply chain (producers at the beginning and consumers at the end) as significantly more important than the parties in intermediate positions in the supply chain (wholesalers, nurseries, retailers, and marketers).

We compare pairwise, through $t$ tests, the ratings of importance of technical considerations and challenges influencing setting of priorities when selecting a trait for inclusion in a breeding program. Results are presented in Tables 4 and 5. Only statistically significant differences are reported and discussed in these tables. Table 4 shows that availability of genetic variation is rated significantly higher and previous research is rated lower than other technical considerations, including environmental effects, resource availability, and expertise availability. In Table 5, we present results comparing pairwise the ratings of importance for challenges faced when determining and implementing breeding program priorities. Breeders rate lack of consistent information on genetic material and lack of genetic material as significantly more challenging than difficult to find consensus across interested parties and poor communication with interested parties. Additionally, socioeconomic challenges such as uncertainty if a cultivar being developed would be commercially viable, difficult to find consensus, and separate short-term from long-term needs are rated significantly higher than poor communications with interested parties. When comparing pairwise the challenges faced when implementing breeding program priorities, breeders assign the highest ratings to the limitation of resources such as funding

Table 1. Summary statistics of the background information of surveyed breeders and breeding programs $(\mathrm{n}=34)$.

\begin{tabular}{llcc}
\hline Category & \multicolumn{1}{c}{ Variable } & Percentage (number of breeders) & SD \\
\hline Crop or crop group & Strawberry & $29 \%(10)$ \\
& Apple & $15 \%(5)$ \\
& Peach & $24 \%(8)$ \\
& Blackberry & $9 \%(3)$ \\
& Red raspberry & $12 \%(4)$ \\
& Non-peach stone fruit ${ }^{\mathrm{z}}$ & $12 \%(4)$ & 10.00 \\
Work years & More than one crop & \\
Program size & Work years & $60 \%(20)$ & 11.82 \\
Program affiliation & Program size & 19.61 & \\
& Private & 9.33 \\
Crop use & University & $18 \%(6)$ & $56 \%(19)$ \\
& Federal & $26 \%(9)$ \\
& Fresh & $62 \%(21)$ & $21 \%(7)$ \\
& Both fresh and processed & $17 \%(6)$
\end{tabular}

${ }^{\mathrm{z}}$ Apricot, plum, sweet cherry, tart cherry.

${ }^{\mathrm{y}} 1$ if the breeder breeds more than one crop and 0 otherwise.

${ }^{\mathrm{x}}$ Number of years breeder professional involved in breeding activities.

${ }^{\mathrm{w}}$ Breeding program size in terms of number of seedlings produced for screening and selection per year (1000 seedlings). 


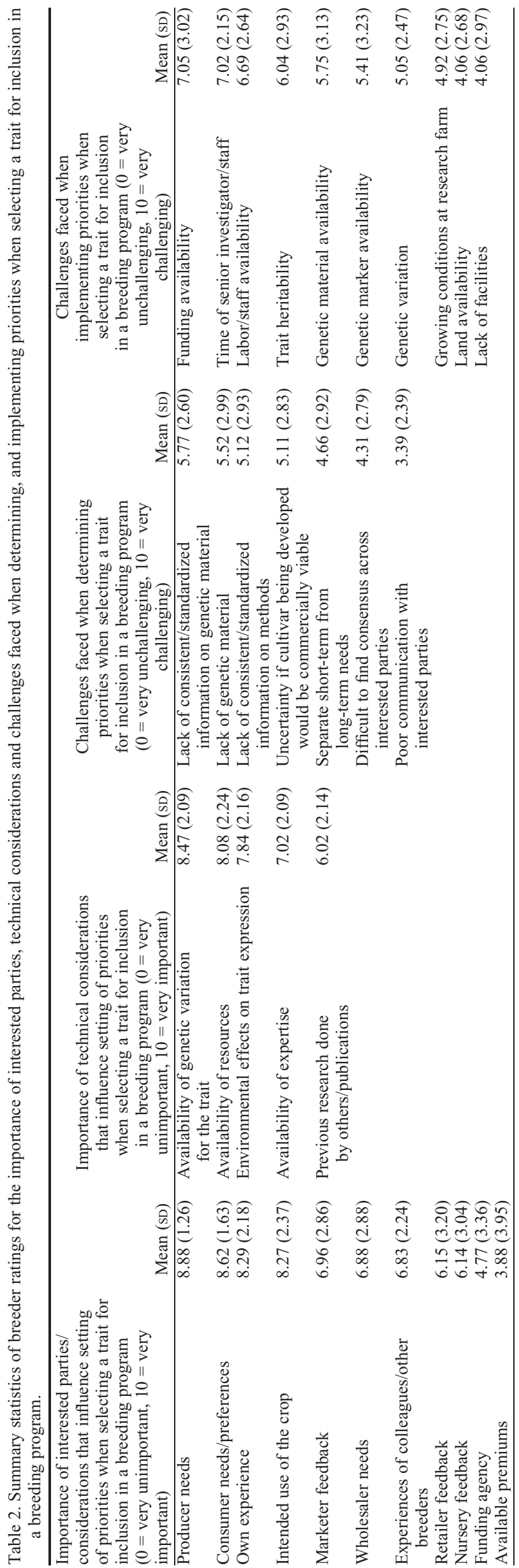

availability, labor/staff availability, and time availability of senior investigator/staff.

Breeders indicate they interacted most frequently with producers followed by other breeders, nurseries, and consumers. However, breeders consider consumer needs as very important in determining the priorities when selecting a trait for inclusion in a breeding program despite interacting less with consumers than with other interested parties. Compared with university and federal breeders, private breeders interact more frequently with different parties along the supply chain, especially wholesalers, marketers, retailers, and consumers. Breeders communicate with stakeholders through formal (e.g., industry conference presentations and field days) and informal conversations. Additionally, 26\% of respondents have an industry advisory panel, whereas only $9 \%$ have a consumer advisory panel.

Tobit model estimation results. To identify the major factors affecting breeder ratings of interested parties, technical considerations, and challenges faced, we ran 33 Tobit models with the parameter estimates presented in Tables 6 to 9. Table 6 contains the results for the 11 dependent variables indicating the importance of interested parties and other factors on priority setting in breeding programs (producers, wholesaler, consumers, nursery, funding agency, own experience, colleagues/other breeders experience, intended use of crop, marketer feedback, retailer feedback, and available premiums). Table 7 includes the results for the five regressions for which the dependent variables are the ratings on the importance of different technical considerations for priority setting (environmental effects on trait expression, availability of genetic variation, availability of resources, availability of expertise, and previous research). The next set of results, in Table 8 , includes seven regressions for which the dependent variables are the different challenges breeders face when determining their programs' priorities. These dependent variables include: lack of consistent/standard information on genetic material; lack of genetic material; lack of consistent information on methods; poor communication with interested parties; no clear separation between short-term and long-term needs; difficult to find consensus across interested parties; and uncertainty if the cultivar developed would be commercially viable. The final 10 regressions in Table 9 pertain to challenges breeders face when implementing priorities. Dependent variables include availability of funding, labor, time of senior investigator, genetic markers, genetic material, trait heritability, genetic variation, land, growing conditions, and facilities.

For all 33 models, the set of independent variables is the same: binary variables for fruit crop type (strawberries, apples, peaches, blackberries, red raspberries, non-peach stone fruits including plums, sweet cherries, tart cherries, and apricots), organization employing the breeder (federal, university, and private), intended use of the crop (fresh 
Table 3. Pairwise $t$ test comparisons for the mean ratings of the importance of interested parties that influence setting of priorities when selecting a trait for inclusion in a breeding program.

\begin{tabular}{|c|c|}
\hline Comparison & $t$ test value ${ }^{z}$ \\
\hline Producer-wholesaler & $5.082^{* * * * y}$ \\
\hline Producer-nursery & $6.253 * * *$ \\
\hline Producer-funding agency & $6.652 * * *$ \\
\hline Producer-marketer & $4.181 * * *$ \\
\hline Producer-retailer & $4.787 * * *$ \\
\hline Producer-available premium & $6.542 * * *$ \\
\hline Wholesaler-consumer & $-3.846 * * *$ \\
\hline Wholesaler-funding agency & $2.475 * *$ \\
\hline Wholesaler-own experience & $-2.148 * *$ \\
\hline Wholesaler-intended use & $-1.814^{*}$ \\
\hline Wholesaler - available premium & $4.274 * * *$ \\
\hline Consumer-nursery & $4.393 * * *$ \\
\hline Consumer-funding agency & $6.251 * * *$ \\
\hline Consumer-colleagues/other breeder & $3.890 * * *$ \\
\hline Consumer-marketer & $3.802 * * *$ \\
\hline Consumer-retailer & $5.126^{* * *}$ \\
\hline Consumer-available premium & $6.976^{* * *}$ \\
\hline Nursery_funding agency & $1.987^{*}$ \\
\hline Nursery-own experience & $-3.564 * * *$ \\
\hline Nursery_-intended use & $-3.537 * * *$ \\
\hline Nursery_available premium & $2.186^{* *}$ \\
\hline Funding agency - own experience & $-5.920 * * *$ \\
\hline Funding agency_colleagues/other breeder & $-3.497 * * *$ \\
\hline Funding agency_-intended use & $-5.873 * * *$ \\
\hline Funding agency-marketer & $-2.691 * *$ \\
\hline Funding agency_retailer & $-2.003 *$ \\
\hline Own experience_colleagues/other breeder & $4.773 * * *$ \\
\hline Own experience-marketer & $2.084 * *$ \\
\hline Own experience-retailer & $2.734 * *$ \\
\hline Own experience_-available premium & $5.213 * * *$ \\
\hline Colleagues/other breeder —intended use & $-3.064 * * *$ \\
\hline Colleagues/other breeder-available premium & $3.213 * * *$ \\
\hline Intended use-marketer & $1.853^{*}$ \\
\hline Intended use-retailer & $2.670 * *$ \\
\hline Intended use - available premium & $5.484 * * *$ \\
\hline Marketer-retailer & $1.838^{*}$ \\
\hline Marketer_available premium & $4.047 * * *$ \\
\hline Retailer-available premium & $2.942 * * *$ \\
\hline
\end{tabular}

${ }^{\mathrm{z}}$ Only statistically significant results are reported.

y***Significant at $1 \%$ level; ** significant at 5\% level; *significant at $10 \%$ level.

Table 4. Pairwise $t$ test comparisons for the mean ratings of technical factors that influence setting of priorities when selecting a trait for inclusion in a breeding program.

\begin{tabular}{lc}
\hline Comparison & $t$ test value $^{z}$ \\
\hline Environmental effects - availability of genetic variation & $-2.004^{* y}$ \\
Environmental effects - expertise availability & $2.095^{* *}$ \\
Environmental effects - previous research & $4.134^{* * *}$ \\
Availability of genetic variation - expertise availability & $3.729^{* * *}$ \\
Availability of genetic variation - previous research & $6.595^{* * *}$ \\
Resource availability - expertise availability & $2.392^{* *}$ \\
Resource availability - previous research & $5.210^{* * *}$ \\
Expertise availability - previous research & $2.465^{* *}$ \\
\hline
\end{tabular}

${ }^{\mathrm{z} O n l y}$ statistically significant results are reported.

y***Significant at $1 \%$ level; **significant at 5\% level; *significant at $10 \%$ level.

market, processed market, and both fresh and processed market), and if the program was multicrop. Continuous variables are program size (characterized as the number of new seedlings produced each year for evaluation) and number of years of experience working as a breeder. To avoid perfect multicollinearity, the variables Non-peach stone fruit (including plum, sweet cherry, tart cherry, and apricot), Organization_federal, and Processed are dropped for estimation purposes and serve as the reference group for interpretation of the estimated coefficients. Thus, all effects described will be relative to the omitted category. In the next sections, we non-peach stone fruit breeders. Apple breeders rate experiences of other colleagues/breeders as more important. Peach, blackberry, and red raspberry breeders rate nursery feedback, own experience, and experiences of other colleagues higher. In addition, peach and red raspberry breeders consider marketer feedback as less important, and red raspberry breeders rate consumer needs, retailer feedback, and available premiums as less important than non-peach stone fruit breeders. Blackberry breeders rated intended use of the crop for processing as more important than non-peach stone fruit breeders. These results reflect how the main crop bred in the program, the crop industry, and the nature of the breeding program per se influence ratings of importance of interested parties and other factors. For example, available premiums in strawberries, peach, and red raspberries could be less important because it is difficult to differentiate cultivars in the marketplace and premiums are typically set for differentiated cultivars. Consistently, nursery feedback is rated important by strawberry, peach, blackberry, and red raspberry breeders probably as a result of the prominent role played by nurseries in commercialization of new cultivars for these crops.

Multicrop breeders rate the feedback from the market (consumer needs, marketer feedback, retailer feedback, and available premiums) as more important, and intended use for processing as less important, compared with breeders working with one crop. Breeders with more years of experience consider consumer needs, retailer feedback, available premiums, and funding agency as less important, whereas intended use of the crop for processing and own experience are rated higher in importance compared with breeders with less experience. This suggests that breeders with more years of experience also have had more contact with supply chain members; thus, they have internalized consumer and retailer needs into their own values more than younger breeders.

Compared with breeders with smaller programs, breeders with larger programs consider feedback from consumers, retailers, and available premiums as well as feedback from nurseries and funding agencies as more important factors. Marketer feedback and available premiums are rated more important and funding agency and nursery feedback less important by private breeders compared with federal breeders. University breeders regard marketer, retailer, available premiums, and own experience as more important compared with federal breeders. Breeders working with fresh market and both fresh and processed markets rate consumer preferences higher and experiences of colleagues lower compared with processed crop breeders. Breeders targeting both fresh and processed markets rate retailer feedback and available premiums as more important than only processed crop breeders.

Overall, we find that market-related factors are most important to long-term breeding crops such as apple and peaches and are relatively less important to short-term crops 
Table 5. Pairwise $t$ test comparisons for the mean ratings of challenges that influence setting of priorities when selecting a trait for inclusion in a breeding program.

\begin{tabular}{|c|c|}
\hline Comparison & $t$ test value ${ }^{z}$ \\
\hline \multicolumn{2}{|c|}{ Pairwise comparison of ratings of importance of challenges for determining priorities } \\
\hline $\begin{array}{l}\text { Lack of consistent information on genetic material-lack } \\
\text { of consistent information on methods }\end{array}$ & $1.960^{* y}$ \\
\hline $\begin{array}{l}\text { Lack of consistent information on genetic material-poor } \\
\text { communication between parties }\end{array}$ & $4.882 * * *$ \\
\hline $\begin{array}{l}\text { Lack of consistent information on genetic material-separate } \\
\text { short-term from long-term needs }\end{array}$ & $2.338 * *$ \\
\hline $\begin{array}{l}\text { Lack of consistent information on genetic material—difficult } \\
\text { to find consensus }\end{array}$ & $2.711 * *$ \\
\hline Lack of genetic material-poor communication between parties & $4.484 * * *$ \\
\hline Lack of genetic material - difficult to find consensus & $2.106^{* *}$ \\
\hline $\begin{array}{l}\text { Lack of consistent information on methods-poor } \\
\text { communication between parties }\end{array}$ & $3.606^{* * *}$ \\
\hline $\begin{array}{l}\text { Poor communication between parties-separate short-term } \\
\text { from long-term needs }\end{array}$ & $-2.956^{* * *}$ \\
\hline Poor communication between parties-difficult to find consensus & $-2.374 * *$ \\
\hline $\begin{array}{l}\text { Poor communication between parties - uncertainty of developing } \\
\text { variety's commercial viability }\end{array}$ & $-3.454 * * *$ \\
\hline \multicolumn{2}{|c|}{ Pairwise comparison of ratings of importance of challenges for implementing priorities } \\
\hline Available funding_-genetic marker availability & $2.216^{* *}$ \\
\hline Available funding - trait heritability & $1.983 *$ \\
\hline Available funding - land availability & $2.862 * * *$ \\
\hline Available funding - growing conditions & $5.968 * * *$ \\
\hline Available funding _ lack of facilities & $4.083 * * *$ \\
\hline Available labor-genetic marker availability & $2.028^{*}$ \\
\hline Available labor_-land availability & $2.536 * *$ \\
\hline Available labor-growing conditions & $4.817 * * *$ \\
\hline Available labor-lack of facilities & $3.171 * * *$ \\
\hline Senior investigator time - genetic marker availability & $2.441 * *$ \\
\hline Senior investigator time - trait heritability & $2.115^{* *}$ \\
\hline Senior investigator time-land availability & $3.528^{* * *}$ \\
\hline Senior investigator time - growing conditions & $6.384 * * *$ \\
\hline Senior investigator time- - lack of facilities & $4.619^{* * *}$ \\
\hline Genetic marker availability - growing conditions & $1.991 *$ \\
\hline Trait heritability - growing conditions & $2.691 * *$ \\
\hline Genetic variation-land availability & $2.727 * *$ \\
\hline Genetic variation - growing conditions & $3.382 * * *$ \\
\hline Genetic variation - lack of facilities & $1.843^{*}$ \\
\hline Land availability - growing conditions & $1.986^{*}$ \\
\hline Growing conditions-lack of facilities & $-2.752 * * *$ \\
\hline
\end{tabular}

${ }^{2}$ Only statistically significant results are reported.

y***Significant at $1 \%$ level; **significant at $5 \%$ level; *significant at $10 \%$ level.

such as strawberries. Similarly, market-related factors are more important to large programs, to private and university-affiliated programs, and when the use of the crop is for the fresh market.

Importance of technical considerations that influence setting of priorities when selecting a trait for inclusion in a breeding program. Results for this section are listed in Table 7. Peach and blackberry breeders consider environmental effects on trait expression, availability of genetic variation for the trait, and availability of resources as more important technical considerations compared with non-peach stone fruit breeders. Strawberry and apple breeders regard availability of expertise as less important. Red raspberry breeders consider environmental effects on trait expression and availability of resources as more important compared with non-peach stone fruit breeders.

Multicrop breeders rate environmental effects on trait expression and availability of genetic variation as less important than single-crop breeders. Breeders with more years of experience consider previous research done by others less important compared with breeders with fewer years of breeders are more challenged by the uncertainty if a cultivar would be commercially viable and peach breeders by the lack of consistent/standardized information on genetic material. Blackberry breeders are more challenged by the uncertainty if a cultivar would be commercially viable and red raspberry by separate short-term from long-term needs.

Breeders with a larger program size are more challenged by lack of consistent/ standardized information on genetic material and methods, poor communication with interested parties, and difficulty in finding consensus across interested parties. Private breeders are less challenged by lack of consistent/standardized information on genetic material and methods and separate short-term from long-term needs compared with federal breeders. Compared with processed crop breeders, breeders breeding for fresh markets are more challenged to separate short-term from long-term goals and difficulties finding consensus across interested parties.

Technical and socioeconomic challenges breeders faced to implement priorities when selecting a trait for inclusion in their breeding programs. Table 9 reports how breeding program characteristics influence the importance of technical and socioeconomic challenges breeders face to implement priorities when selecting a trait for inclusion in a breeding program. Compared with non-peach stone fruit breeders, strawberry breeders are impacted more by the time limitations of the senior investigator/staff but less by the availability of genetic material, trait heritability, genetic variation, and lack of facilities. Genetic variation is of less concern to apple breeders and lack of facilities is of less concern to blackberry breeders. (We used the term "genetic variation" without qualification in the survey. We did not make reference to lack or abundance. Apple breeders apparently felt they had sufficient genetic variation and for them, this was not an important limiting factor.) Labor/staff availability is more challenging to peach and red raspberry breeders and genetic marker availability is more challenging to peach breeders.

Breeders with more years of experience are more challenged by lack of genetic variation and less challenged by genetic markers availability than breeders with fewer years of experience. Breeders with a larger program size are less challenged by the time limitations of the senior investigator. This could be the result of greater access to more support personnel. Private breeders are less challenged by resource limitations such as funding availability, labor/staff availability, land availability, lack of facilities, and genetic markers availability. Both private and university breeders are more challenged by time of senior investigator/ staff compared with federal breeders. Breeders in each sector would have various pressures on their time. University breeders often have either classroom and/or extension education as part of their responsibilities. Private sector breeders are often involved in outreach to 

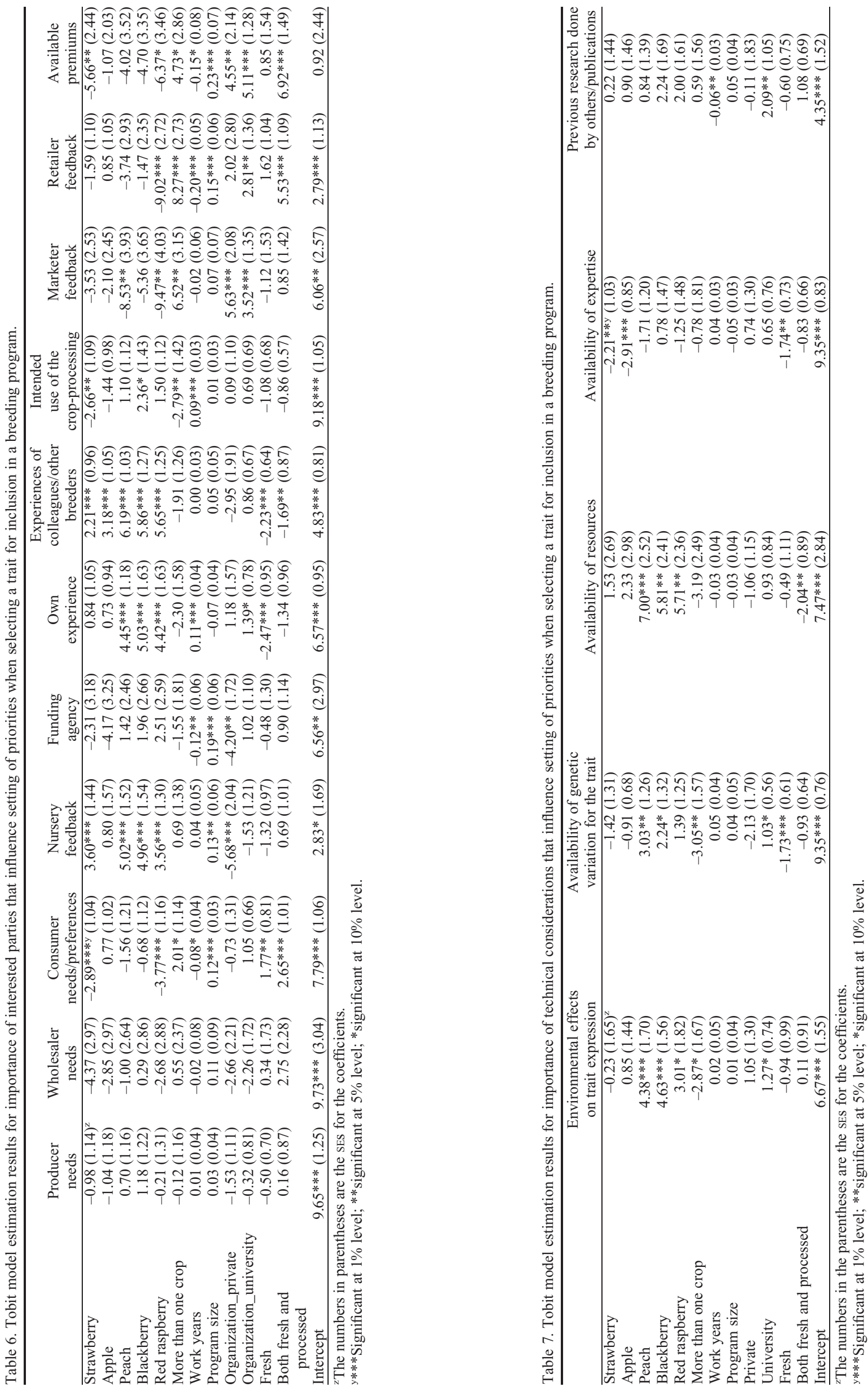


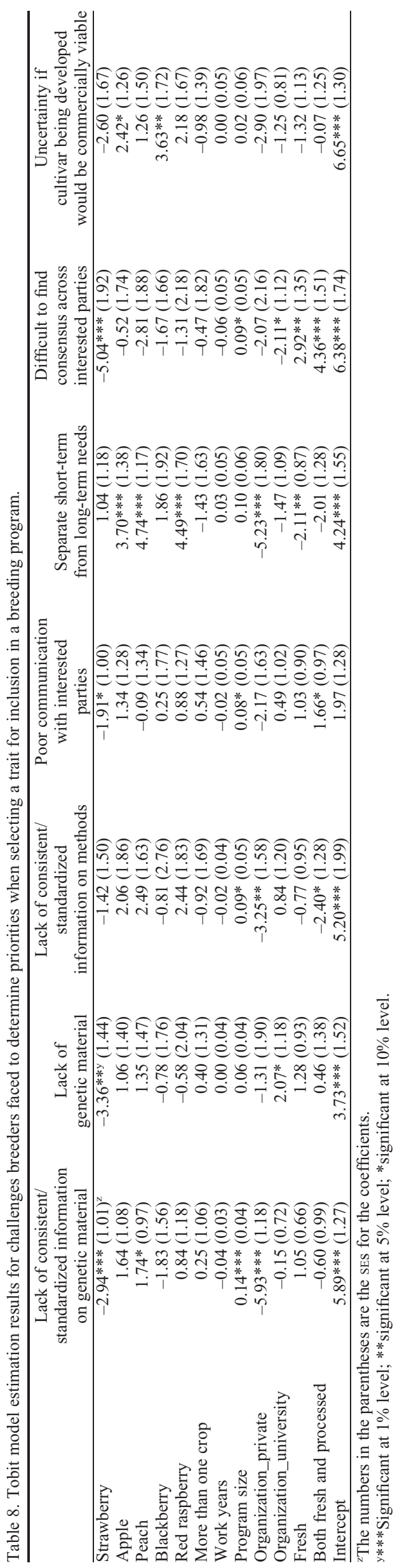

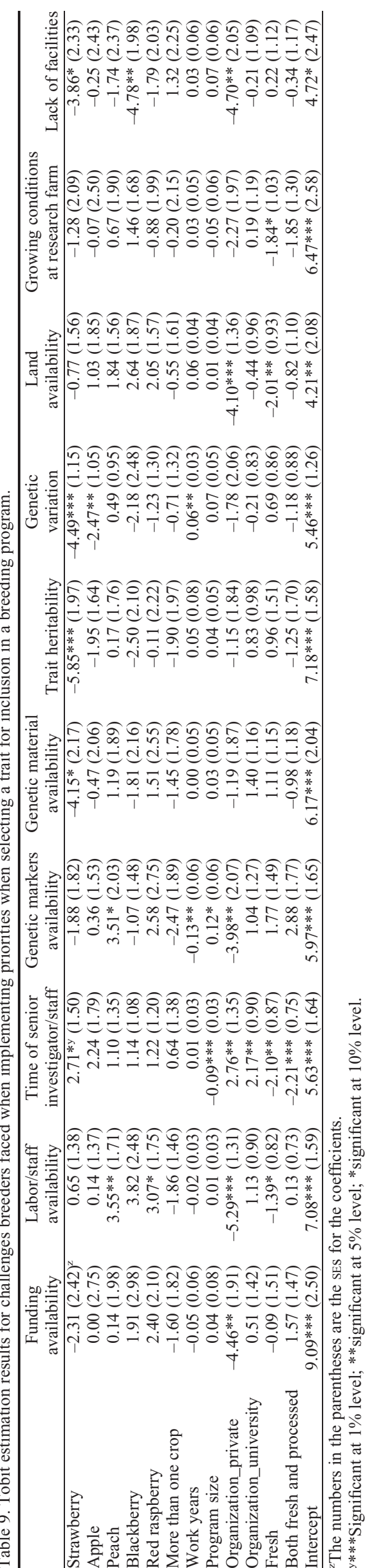

HortScience Vol. 47(9) September 2012 
growers, although this is often directly related to disseminating information about their breeding programs and cultivars, whereas federal breeders are typically expected to focus on their research. Compared with breeders who breed for processed markets, breeders targeting fresh markets are less challenged by labor/ staff availability, time limitations of senior investigator/staff, land availability, and growing conditions at the research farm.

\section{Discussion and Conclusions}

Long-term breeding programs like those in rosaceous crops have a higher proportion of public sector breeding programs than vegetable and agronomic crops (Frey, 1996), so they are disproportionately affected by ongoing declines in federal and state funding. As programs seek to apply genomics and molecular biological tools to improve their efficiency and retain or gain market share, it is more important than ever to understand how programs' priorities are determined and implemented. Results of this study provide breeders, funding agencies, and policymakers with valuable information that can help them better understand how particular program characteristics (e.g., program size, organization affiliation, single or multicrop, type of crop, use of the crop, etc.) affect the perception of the importance of interested parties' needs and the importance of societal and technical challenges when determining and implementing priorities.

Overall, we find that breeders rate marketrelated factors higher than other influencing (interested parties) factors. Market-related factors include consumer needs, intended use of the crop, marketer and retailer feedback, and available premiums. This finding indicates that breeders recognize and prioritize the notion that for a new cultivar to be successful, it must be widely accepted by consumers, thus displaying a market-driven vision. However, this varies among program characteristics. For example, market-related factors are more important to non-peach stone fruit and apple programs, to large programs, to private and university-affiliated programs, and when the use of the crop is for the fresh market. Typically, breeding programs are not responsible for the marketing strategy of their new cultivar releases and have little opportunity to observe consumers' direct response (recall only nine programs have their own consumer panel). Programs with more resources (i.e., large-scale and private) are more likely to receive indirect information from independent market intermediaries, marketers in their own organization, to have their own consumer panels, or to establish on-site collaborations with food sensory scientists. University and federal breeding programs have growers' organizations as important funding sources. These breeders regularly interact with growers to report research progress and often conduct field trials with grower-cooperators, so they have opportunities for regular interaction with producers. Breeding programs are located in various production regions across the United States and Canada, typically in small towns with populations of limited size and diversity compared with the national or global market for their crop. Thus, these programs receive less direct feedback from consumers compared with producers, because they have limited resources in terms of time and funding to systematically access consumer feedback.

This study provides cues to identify how different breeding programs characteristics influence how technical and societal challenges affect programs' priority setting. For example, the information in this study highlights the importance of incorporating a market-driven vision to small-scale and federal programs to consistently foster the delivery of commercially successful cultivars. In addition, our findings document that rosaceous crop breeding programs face a diverse array of challenges, most of them resource-related. Societal challenges are deemed as important as resource-related challenges, albeit less so than some technical challenges. We argue that societal challenges could be addressed by collecting information and assessing values on marketing chain stakeholders' perceptions on the genetic traits of importance for successful cultivars, underscoring the importance of complementing breeders' work with social science approaches.

To our knowledge, this is the first study to provide a comprehensive assessment of North
American rosaceous crop breeding programs and the technical and socioeconomic challenges breeders face when determining and implementing selection priorities. Our findings support the need for funding programs to encourage a system-based approach with transdisciplinary components like agricultural economists and food scientists in sensory evaluation to develop more market-driven breeding programs. Our findings also lead to a number of questions concerning the reasons for the observed differences across programs or the lack thereof. Further research is needed to explore in-depth these reasons and to assess effective ways to tackle challenges presented to breeders.

\section{Literature Cited}

Dirlewanger, E., P. Cosson, M. Tavaud, M.J. Aranzana, C. Poizat, A. Zanetto, P. Arús, and F. Laigret. 2002. Development of microsatellite markers in peach [Prunus persica (L.) Batsch] and their use in genetic diversity analysis in peach and sweet cherry (Prunus avium L.). Theor. Appl. Genet. 105:127-138.

Gallardo, R.K., D. Nguyen, V. McCracken, C. Yue, J. Luby, and J. McFerson. 2012. An investigation of trait prioritization in rosaceous fruit breeding programs. HortScience 47:771-776.

Frey, K.J. 1996. National plant breeding study. I. Human and financial resources devoted to plant breeding research and development in the United States in 1994. Spec. Rpt. 98. Iowa Agr. Home Econ. Expt. Sta., Iowa State Univ. with Coop. State Res., Educ. and Ext. Serv., U.S. Dept. Agr.

Greene, W. 2007. Econometric analysis. 6th Ed. Prentice Hall, Upper Saddle River, NJ.

McCullough, D. 1998. Web-based market research: The dawning of a new age. Direct Marketing 61:36-38.

McFerson, J. 2010. Breeders seek input from supply chain. Good fruit grower, Dec. 2010 2012 Jan. <http://www.goodfruit.com/GoodFruit-Grower/December-2010/Breeders-seekinput-from-supply-chain/>

Shulaev, V., S.S. Korban, B. Sosinski, A.G. Abbott, H.S. Aldwinckle, K.M. Folta, A. Iezzoni, D. Main, P. Arús, A.M. Dandekar, K. Lewers, S.K. Brown, T.M. Davis, S.E. Gardiner, D. Potter, and R.E. Veilleux. 2008. Multiple models for rosaceae genomics. Plant Physiol. 147:985-1003.

Solomon, M.R. and E. Stuart. 2003. Marketing: Real people, real choices. $5^{\text {th }}$ Ed. Prentice Hall, Upper Saddle River, NJ. 